\title{
New developments in the characterization of heparin and its impurities
}

\author{
Cynthia K. Larive
}

Published online: 30 November 2010

(C) The Author(s) 2010. This article is published with open access at Springerlink.com

This special issue highlights many aspects of heparin characterization. Heparin, a glycosaminoglycan, is both an important pharmaceutical in it is own right and a pharmaceutical target for drug discovery as it mediates a wide range of biological processes. A potent anticoagulant isolated from porcine intestinal mucosa, approximately one billion pigs a year are required to constitute the heparin supply. In early 2008 , a contaminant was apparently intentionally introduced into the supply of heparin coming from China. This contaminant, oversulfated chondroitin sulfate (OSCS), had many of the same chemical properties as heparin, allowing contaminated lots to pass the quality assurance screens in place at the time. Although it mimicked the anticoagulant properties of heparin, unfortunately, OSCS also produced acute allergic-type reactions in dialysis patients, leading to more than 200 deaths worldwide. The US Food and Drug Administration has recommended the further development of additional methods for the analysis of heparin purity, and the analytical chemistry community rapidly responded to this challenge. Along with critical reviews discussing the characterization of heparin impurities and hyphenated methods for heparin analysis, this special issue highlights many innovative approaches for the detection and characterization of heparin impurities, including NMR, strong anion exchange HPLC, fluorescence spectroscopy, circular dichroism, PCR, and electrochemical sensing.

Other contributions to this special issue address the challenges of glycomics through the development of analytical methods for the molecular-level characterization

C. K. Larive $(\bowtie)$

Department of Chemistry, University of California,

Riverside, CA 92521, USA

e-mail: clarive@ucr.edu of heparin and related glycosaminoglycans. Articles in this special issue focus on the use of stable isotope labeling for advancing structural heparinomics, LC-MS methods for targeted glycomics, determination of the carboxylate $\mathrm{p} K_{\mathrm{a}}$ 's of heparin oligosaccharides, the use of NMR to monitor heparin enzymatic depolymerization reactions, and size exclusion chromatography with dynamic light scattering for the characterization of low-molecular-weight heparin. In addition, a paper in this issue discusses the analysis of Escherichia coli K5 capsular polysaccharide heparosan, a potential future replacement for animal-derived heparin.

In addition to the areas described above, this issue also includes articles that address the biochemical behavior of heparin. In some instances, for example in cases of heparin overdose or in open heart surgery, the heparin that was administered to prevent clotting during the procedure must be neutralized to allow resumption of normal clotting function. A paper in this special issue discusses the efficacy of neutralization of low-molecular-weight heparins and their oligosaccharide components by protamine. In addition, a paper at the forefront of bioanalytical chemistry reports on the preparation of heparin-immobilized microspheres and the characterization of their cytokine binding properties by flow cytometry.

This special issue provides a broad sampling of the current state of the art for heparin analysis and characterization. However, the area of glycomics is a vibrant and rapidly moving field, and we look forward to many new analytical advances in the coming years.

Open Access This article is distributed under the terms of the Creative Commons Attribution Noncommercial License which permits any noncommercial use, distribution, and reproduction in any medium, provided the original author(s) and source are credited. 


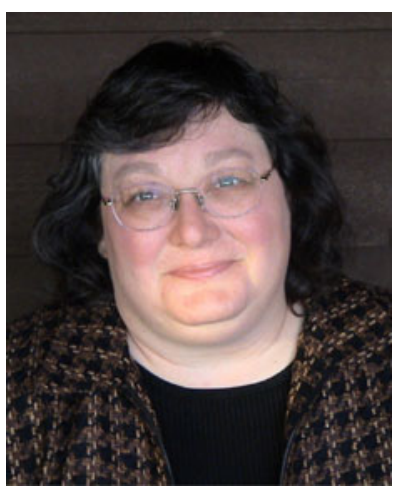

Cynthia Larive is Professor of Analytical Chemistry at the University of California Riverside. She has an active research program involving bioanalytical and environmental analytical applications of NMR Spectroscopy (for more information see http://www.chem.ucr.edu.faculty/ larive/larive.html). Professor Larive is also active in curricular reform and the promotion of undergraduate research. She is editor-in-chief and principal investigator of the Analytical Sciences Digital Library (http://www.asdlib.org), an Internet-based resource for instructors, students, and practitioners of analytical chemistry. This digital library is a collection of peer-reviewed web sites on topics including pedagogical approaches, analytical techniques, applications, and classroom resources. 